\title{
$\rightarrow$ \\ Antisense oligonucleotides and the rational design of new antitumor drugs
}

The development of new effective drugs against cancer is extremely time-con-

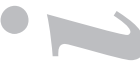
suming and resource-costly. For colon cancer, as for many other tumors, this goal is far from accomplished nowadays despite considerable effort. High costs should include, as a relevant issue, the high number of agents to be assessed and then discarded along the various stages of selection. To render this search more efficient, both official agencies and private ventures tend to rationalize this sort of projects from the start (1). Aside from the major contribution of large-scale empirical analysis using substance banks, there is now the option of searching for drugs specifically directed to increasingly well-defined therapeutic targets. In this respect, currently ongoing advances in the fields of genomics and proteomics allow to recognize an increasingly well-detailed profile of genes as preferentially expressed by tumor tissues (2). A most direct approach is the inhibition of the expression of genes involved in the pathogenesis of a specific tumor type. In this sense, oncogenes such as $\mathrm{K}$-Ras or the telomerase catalytic subunit (TERT) gene are preferential candidates, as both have been involved in malignant phenotype development for a high percentage of colon cancers $(3,4)$. In the article by Lledó et al. (5) being published in this issue, the strategy selected for such inhibition is the use of antisense oligonucleotides (ASO). These are artificial DNA sequences complementary to those of the messenger RNA corresponding to the gene whose inhibition is attempted (6). Several mechanisms account for the blocking of gene expression, with the most widely spread and studied being the degradation of RNA-DNA hybrids by cell nucleases such as RNAse H. The therapeutic potential of such scientifically smart approach is dependent on a number of determining factors.

In the first place one must be certain that inhibiting the target gene will result in the death of tumor cells or at least a reversal of their malignant phenotype. For colon cancer, a need to accumulate successive mutations so that tissue may progressively acquire cancer characteristics has been established (7). An activation of selected oncogenes is needed to increase cell proliferation rates or alter control systems thus allowing the development of new mutations, but this activation may possibly become dispensable for tumor growth later on. Fortunately though, evidence suggests that both TERT and Ras oncogene inhibition may bring about the death of cancer cells on its own. Telomerase is a ribonucleoprotein complex whose better established function is the synthesis of repeat sequences at the ends of chromosomes (telomers) (8). Since these ends become progressively shorter as a consequence of each cell division, the number of divisions most somatic cells may endure is restricted by telomer length. In this way, tumor cells require a mechanism (telomerase) to keep telomer length despite restless cell division. Along this line, it would seem only logical that telomerase expression blockade in tumor cells would ultimately af- 
fect their growth rate when telomeric repeats finally run out (9). However, efficient inhibition of telomerase expression has been seen to potentially induce apoptosis in a few days $(10,11)$, and this is irrespective of its traditional telomer-lengthening function. It has been currently suggested that, in addition to this function, telomerase may be necessary to protect chromosome ends against their being acknowledged as DNA disruptions, which would trigger mechanisms for apoptosis or cell cycle termination (12). This notion is consistent with recent findings demonstrating transient low-level telomerase expression during the $\mathrm{S}$ phase in non-modified human somatic cells (13). In view of these reports, the need to assess the effect complete, permanent inhibition of telomerase may exert on normal cells stands out. Regarding Ras inhibition, the potential to induce cell death may partly depend on a restoration of the p53 route, which was previously repressed by Ras (14). Through Ras actions tumor cells under several genetic and metabolic insults may survive and divide despite such strong proapoptotic stimuli. However, just because of tumor cells' severe unstability, their ability to select mutants adapted to the inhibition of specific routes is very high. In this respect the approach described by Lledó et al. (5), based on the simultaneous inhibition of several tumorigenic mechanisms using ASOs, is most interesting. This strategy is reminiscent of the association of several chemotherapeutic agents in order to overcome the resistance of tumor cells to apoptosis.

Secondly, the possibility to reach in vivo an adequate level of inhibiting molecules to reproduce effects seen under cell culture conditions should be assessed, considering that many other factors may reduce treatment efficacy in humans. As an example, ISIS 2503, an ASO designed to counter H-ras oncogene, has been clinically used at doses above $6 \mathrm{mg} / \mathrm{kg} /$ day intravenously, which resulted in plasma levels of $4 \mu \mathrm{g} / \mathrm{ml}$ (15). This would have been theoretically equivalent to an intratumoral concentration greater than $0.1 \mu \mathrm{mol} / \mathrm{l}$, which is the average $\mathrm{IC}_{50}$ reported in vitro for most tumor cells. However, no clear antitumoral effect could be demonstrated. Vectors may be an alternative in order to improve ASO bioavailability. From a pharmacological viewstand this increases system complexity and may result in new difficulties. However, the power, stability, and antitumoral specificity of vectors chosen will determine not only the biological effects on tumor cells, but also the presence or absence of adverse effects on surrounding tissues.

\title{
J. Prieto and R. Hernández-Alcoceba
}

\author{
Centro de Investigación Médica Aplicada (CIMA). Unit of Genic Therapy and
} Hepatology. Facultad de Medicina-FIMA. Pamplona, Navarra. Spain

\section{References}

1. Suggitt M, Bibby MC. 50 years of preclinical anticancer drug screening: empirical to target-driven approaches. Clin Cancer Res 2005; 11: 971-81.

2. Kleivi K, Teixeira MR, Eknæs M, Diep CB, Jakobsen KS, Hamelin R, et al. Genome signatures of colon carcinoma cell lines. Can Gen Cytogen 2004; 155: 119-31.

3. Dong SM, Traverso G, Johnson C, Geng L, Favis R, Boynton K, et al. Detecting colorectal cancer in stool with the use of multiple genetic targets. J Natl Cancer Inst 2001; 93: 858-65.

4. Niiyama H, Mizumoto K, Sato N, Nagai E, Mibu R, Fukui T, et al. Quantitative analysis of hTERT mRNA expression in colorectal cancer. Am J Gastroenterol 2001; 96: 1895-900. 
5. Lledó S, Alfonso R, Aliño SF. Eficacia de la terapia génica antisentido utilizando anti K-ras y anti telomerasa en cáncer colorrectal (CCR). Rev Esp Enferm Dig 2005; 97 (7): 472-80.

6. Dean NM, Bennett CF. Antisense oligonucleotide-based therapeutics for cancer. Oncogene 2003; 22: 9087-96.

7. Lipton L, Halford SE, Johnson V, Novelli MR, Jones A, Cummings C, et al. Carcinogenesis in MYH-associated polyposis follows a distinct genetic pathway. Cancer Res 2003; 63: 7595-9.

8. Blackburn EH. Telomeres and telomerase: their mechanisms of action and the effects of altering their func-tions. FEBS Lett 2005; 579: 859-62.

9. Corey DR. Telomerase inhibition, oligonucleotides, and clinical trials. Oncogene 2002; 21: 6317.

10. Saretzki G, Ludwig A, von Zglinicki T, Runnebaum IB. Ribozyme-mediated telomerase inhibition induces immediate cell loss but not telomere shortening in ovarian cancer cells. Cancer Gene Ther 2001; 8: 827-34.

11. Folini M, Brambilla C, Villa R, Gandellini P, Vignati S, Paduano F, et al. Antisense oligonucleotide-mediated inhibition of hTERT, but not hTERC, induces rapid cell growth decline and apoptosis in the absence of telomere shortening in human prostate cancer cells. Eur J Cancer 2005; 41: 624-34.

12. Blakburn EH. Telomere states and cell fates. Nature 2000; 408: 53-6.

13. Masutomi K, Yu EY, Khurts S, Ben-Porath I, Currier JL, Metz GB, et al. Telomerase maintains telomere structure in normal human cells. Cell 2003; 114: 241-53.

14. Halaschek-Wiener J, Wacheck V, Kloog Y, Jansen B. Ras inhibition leads to transcriptional activation of p53 and down-regulation of Mdm2: two mechanisms that cooperatively increase p53 function in colon cancer cells. Cell Signal 2004; 16: 1319-27.

15. Cunningham CC, Holmlund JT, Geary RS, Kwoh TJ, Dorr A, Johnston JF, et al. A Phase I trial of H-ras anti-sense oligonucleotide ISIS 2503 administered as a continuous intravenous infusion in patients with advanced carcinoma. Cancer 2001; 92: 1265-71. 